\title{
Understanding the obstacle of incompatibility at residue 156 within HLA-B*35 subtypes
}

\author{
Trishna Manandhar ${ }^{1} \cdot$ Heike Kunze-Schumacher ${ }^{1} \cdot$ Trevor Huyton $^{1}$. \\ Alexander A. Celik ${ }^{1} \cdot$ Rainer Blasczyk ${ }^{1} \cdot$ Christina Bade-Doeding $^{1}$
}

Received: 16 November 2015 / Accepted: 23 December 2015/Published online: 12 January 2016

(C) The Author(s) 2016. This article is published with open access at Springerlink.com

\begin{abstract}
Defining permissive and non-permissive mismatches for transplantation is a demanding challenge. Single mismatches at amino acid (AA) position 156 of human leucocyte antigen (HLA) class I have been described to alter the peptide motif, repertoire, or mode of peptide loading through differential interaction with the peptide-loading complex. Hence, a single mismatch can tip the balance and trigger an immunological reaction. HLA-B*35 subtypes have been described to evade the loading complex, 156 mismatch distinguishing $\mathrm{B} * 35: 01$ and $\mathrm{B} * 35: 08$ changes the binding groove sufficiently to alter the sequence features of the selected peptide repertoire. To understand the functional influences of residue 156 in $B^{*} 35$ variants, we analyzed the peptide binding profiles of HLA-B*35:01 ${ }^{156 \mathrm{Leu}}, \mathrm{B}^{*} 35: 08^{156 \mathrm{Arg}}$ and B*35:62 $2^{156 \text { Trp }}$. The glycoprotein tapasin represents a target for immune evasions and functions within the multimeric peptide-loading complex to stabilize empty class I molecules and promote acquisition of high-affinity peptides. All three $B * 35$ subtypes showed a tapasin-independent mode of peptide acquisition. HLA-B*35-restricted peptides of low- and high-binding affinities were recovered in the presence and absence of tapasin and subsequently sequenced utilizing mass spectrometry. The peptides derived from $B * 35$ variants differ substantially in their features dependent on their mode of recruitment; all peptides were preferentially anchored by Pro at
\end{abstract}

Electronic supplementary material The online version of this article (doi:10.1007/s00251-015-0896-4) contains supplementary material, which is available to authorized users.

Christina Bade-Doeding

bade-doeding.christina@mh-hannover.de

1 Hannover Medical School, Institute for Transfusion Medicine, Feodor-Lynen-Str. 5, 30625 Hannover, Germany p2 and Tyr, Phe, Leu, or Lys at $\mathrm{p} \Omega$. However, the Trp at residue 156 altered the $\mathrm{p} 2$ motif to an Ala and restricted the $\mathrm{p} \Omega$ to a Trp. Our results highlight the importance of understanding the impact of key micropolymorphism and how a single AA mismatch orchestrates the neighboring AAs.

Keywords HLA polymorphism · Peptide-loading complex · Tapasin $\cdot$ Peptide-binding motif

\section{Introduction}

Hematopoietic stem cell transplantation (HSCT) is widely used as a curative therapy for various hematological malignancies and immune-related disorders (Blazar et al. 2012). Human leucocyte antigens (HLAs) still remain the main barrier for unrelated HSCT, since HLA molecules are characterized by an extensive genetic diversity (Robinson et al. 2015). HLA molecules are scanning the intracellular proteomic content for peptides of self- or non-self origin, bind selected peptides in the peptide-binding region (PBR), and present them to the immune system. Most of the polymorphisms distinguishing allelic variants are located in the PBR, determining the sequence of bound peptides. Every single peptideHLA complex displays a target for $\mathrm{CD}^{+}$immune effector cells. It becomes obvious that a stringent HLA matching between donor and recipient is the most important criteria to be considered in transplantation. It could be demonstrated that best outcomes post-transplantation have been achieved using HLA identical sibling donor:recipient pairs, whereas HLA mismatching might lead to serious transplantation complications including graft-versus-host disease (GvHD), graft rejection, and/or mortality (Hauzenberger et al. 2008; Shaw 2008). Rejection episodes occur when the transplanted donor-derived $\mathrm{T}$ cells trigger allorecognition of incompatible recipient 
antigens following HSCT (Goker et al. 2001; Wood and Goto 2012). The chance of finding an identical donor for HSCT is still only $30 \%$ in the Caucasian population (Pidala et al. 2013); hence, in most cases, HLAmismatched transplants cannot be avoided. Thereby, it is imperative to systematically analyze the differential magnitude of mismatches between HLA subtypes to enable an intelligent mismatching.

Every single HLA-bound peptide alters the accessible surface of the peptide-HLA complex (Burrows et al. 2007) that is presented to immune effector cells; for that reason, the investigation of the individual peptide repertoire and allele-specific peptide-binding profile is the first step to understand and predict histocompatibility. Here, the limiting factors for the selection of a given peptide from the intracellular proteomic pool are (i) the interaction between the HLA and proteins of the peptide-loading complex (PLC) and (ii) the amino acid (AA) composition within the PBR, determining the sequence of a bound peptide. Intracellular peptide loading onto HLA class I molecules in the endoplasmic reticulum (ER) requires the PLC, including the chaperone calreticulin (CRT), thiol-dependent ERp57, transporter associated with antigen processing (TAP), and the HLA class I-dedicated tapasin (TPN) (Ackerman and Cresswell 2004; Wearsch and Cresswell 2008).

TPN is an endoplasmic reticulum (ER) resident transmembrane glycoprotein that exists as a disulfide-linked heterodimer with ERp57 (Dick et al. 2002) and acts in coordination with other components of the PLC to mediate optimal peptide loading, peptide editing, and preferential selection of stable HLA class I complexes (Elliott and Williams 2005; Wearsch and Cresswell 2007). Thus, peptide selection and loading with the assistance of TPN results in the presentation of peptideHLA complexes with long half-life; most HLA allotypes are highly dependent on TPN for peptide presentation. However, few class I allotypes are able to load peptides independently of TPN; TPN independency is conferred by distinct AA compositions within the HLA heavy chain (hc). A single mismatch at a given position can induce TPN independency. Distinct HLA class I alleles show a unique profile of TPN dependence for peptide loading and cell surface expression, depending on the nature of AAs located on certain polymorphic sites within or outside the PBR (Badrinath et al. 2012; Park et al. 2004). Studies revealed that mismatches located at positions 114 (Park et al. 2003), 116 (Williams et al. 2002), or 156 (Badrinath et al. 2012) in the PBR significantly impact the TPN dependency of certain HLA class I molecules.

Micropolymorphism at residue 156 for HLA-B*44 subtypes has been described to strongly impact on immune responses such as an alteration of the mode of peptide loading (Badrinath et al. 2012), an alteration of the allele-specific peptide repertoire (Fleischhauer et al. 1994), and/or the triggering of T cell alloresponses (Badrinath et al. 2014; Keever et al. 1994). All of these immunological events have the potential to cause graft rejection following HSCT (Fleischhauer et al. 1990).

HLA-B*35 belongs to an allelic group with more than 180 alleles. HLA-B*35 molecules are expressed by approximately $20 \%$ of Caucasians with the most frequent one being HLAB*35:01 ${ }^{156 \mathrm{Leu}}$ (9\% of Caucasians) (Marsh et al. 2000; Ragupathi et al. 1995). Within the HLA-B*35 group, three naturally occurring allotypes exhibit a single AA exchange at position 156 (HLA-B*35:01 ${ }^{156 \mathrm{Leu}}, \mathrm{B}^{*} 35: 08^{156 \mathrm{Arg}}$, and $\left.B * 35: 62^{156 \text { Trp }}\right)$. The allotypes HLA-B*35:01 and $B * 35: 08$ have been described to bind peptides of viral (human cytomegalovirus (HCMV) or Epstein-Barr virus (EBV)) origin; the existence of $T$ cells recognizing these pHLA-B*35 could be verified indicating a role of this HLA subtypes in viral immunity. Natural presentation of the described viral peptides by HLA-B*35 alleles has not been observed, yet. However, probable epitopes were mapped using various cell-based assays to demonstrate the function of $\mathrm{T}$ cells against the viral pHLA-B*35 complexes (McAulay et al. 2009; Rickinson and Moss 1997). Notably, even though $B * 35: 01$ and $B * 35: 08$ exclusively differ at residue 156 , both alleles bind different peptides. The peptides that can trigger $\mathrm{T}$ cell responses when bound to HLA-B*35:01 include HCMV pp65 (IPSINVHHY) (Gavin et al. 1993), EBV EBNA1 (HPVGEADYFEY) (Liu et al. 2014), or EBV BZLF1 (LPEPLPQGQLTAY) (Tynan et al. 2005a). HLA-B*35:08 in complex with HCMV pp65 (CPSQEPMSTYVY) (Wynn et al. 2008), HCMV pp65 (FPTKDVAL) (Wynn et al. 2008), or EBV BZLF1 (LPEPLPQGQLTAY) (Tynan et al. 2005a) elicit strong $T$ cell responses similarly. The ability of these HLA-B*35 alleles to trigger T cell responses when bound to a viral peptide could be suggestive of their possible roles in overcoming the dependence on the classical HLA class I presentation pathway and thus viral immune evasion strategies. In order to understand the structural implication of the 156 mismatch for $B * 35: 01$ and $B * 35: 08$, crystal structures of HLA-B*35:01 ${ }^{156 \text { Leu }}$ and $\mathrm{B} * 35: 08^{156 \mathrm{Arg}}$ bound to the same ligand have been solved (Burrows et al. 2007; Green et al. 2004; Tynan et al. 2005b). The distinct structural disparity of these allelic mismatched variants explained their differential peptide selection and consequently their immunogenic incompatibility.

This study was carried out to investigate the functional impact of micropolymorphism at position 156 for HLA*B35 subtypes. We utilized soluble HLA technology (Kunze-Schumacher et al. 2014) in order to analyze the peptide-binding profiles of the three alleles HLA-B*35:01 $1^{156 \mathrm{Leu}}, \mathrm{B}^{*} 35: 08^{156 \mathrm{Arg}}$, and $\mathrm{B} * 35: 62^{156 \mathrm{Trp}}$. The knowledge of allele-specific peptide-binding motifs and repertoires facilitates peptide prediction for 
vaccination purposes and for defining mismatching scores in transplantation.

\section{Materials and methods}

\section{Cell lines}

The lymphoblastoid cell lines (LCLs) $721.220\left(\mathrm{HLA}^{-} /\right.$ $\left.\mathrm{TPN}^{-} / \mathrm{TAP}^{+}\right), 721.221\left(\mathrm{HLA}^{-} / \mathrm{TPN}^{+} / \mathrm{TAP}^{+}\right)$, and $\mathrm{T} 2$ $\left(\mathrm{HLA}^{+} / \mathrm{TPN}^{+} / \mathrm{TAP}^{-}\right)$were used for transduction of recombinant HLA-B*35/156 constructs. The cell lines were maintained in RPMI 1640 medium (Lonza, Verviers, Belgium) supplemented with $10 \%$ heatinactivated fetal calf serum (FCS; Lonza, Verviers, Belgium) and $200 \mathrm{mM}$ glutamine (c.c.pro, Oberdorla, Germany). Human embryonic kidney 293 T cells (HEK293T) were cultured in DMEM (Lonza, Verviers, Belgium) supplemented with $10 \%$ heat-inactivated FCS, $20 \mathrm{mM}$ L-glutamine, $1 \mathrm{mg} / \mathrm{ml}$ penicillin-streptomycin (c.c.pro, Oberdorla, Germany), and $1 \mathrm{mg} / \mathrm{ml} \mathrm{G} 418$ (Gibco/Life Technologies GmbH, Darmstadt, Germany). All cell lines were maintained at $37{ }^{\circ} \mathrm{C}$ in an atmosphere of $5 \% \mathrm{CO}_{2}$.

\section{Construction of lentiviral vectors}

For expression of full length (m) HLA-B*35:01 (exons 1-7) molecules, HLA-B*35:01+ cDNA was amplified by PCR using the primers HLA-B 1 - TAS ( $5^{\prime}$ GAGATGCGGGTCACGGCG-3') and HLA-B-TAAS-E7 (5'-TCAAGCTGTGAGAGACACATCAG-3'). The PCR product was cloned into the lentiviral vector pRRL.PPT.SF.pre.V5-His as previously described (Badrinath et al. 2014). The vectors pRRL.mHLA-B*3508 and pRRL.mHLA-B*3562 were generated by site-directed mutagenesis (SDM) using the primers Sdm_B3508_156_F (5'-GTGGCGGAGCAGCGGAGAGCCTACC-3') and

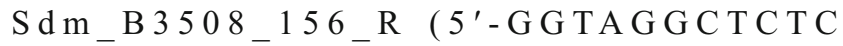
CGCTGCTCCGCCAC-3') or Sdm_B3562_156_F (5'GTGGCGGAGCAGTGGAGAGCCTACCTG-3') and S d m_B $3562 \_156 \_$R ( $5^{\prime}$ - C A G G T A G G C TCTCCACTGCTCCGCCĀC- $3^{\prime}$ ).

Vectors encoding for soluble (s)HLA-B*35/156 variants were generated from $p R R L$.mHLA-B*35/156 vectors by introducing a stop codon using the primers Sdm_B35_sE4_F (5'-CCTCACCCTGAGATGAGAGCCATCTTCCCAGTC$\left.3^{\prime}\right)$ and Sdm_B 35 sE 4_R (5'-GACTGGGA AGATGGCTCTCATCTCAGGGTGAGG-3').

Verification of HLA-B*35/156 inserts was performed by DNA sequencing using an ABI Prism 3730 DNA Analyzer (Applied Biosystems GmbH, Darmstadt, Germany). Subsequently, endotoxin-free plasmid DNA was purified using the
EndoFree ${ }^{\circledR}$ Plasmid Maxi Kit (Qiagen GmbH, Hilden, Germany).

\section{Recombinant eukaryotic cell lines}

LCLs 721.220 and 721.221 or T2 cells were transduced with lentiviral particles encoding for recombinant mHLA-B*35/ 156 (exons 1-7) or sHLA-B*35/156 (exons 1-4) molecules as described previously (Badrinath et al. 2012). Using Lipofectamine $^{\circledR} 2000$ (Invitrogen/Life Technologies GmbH, Darmstadt, Germany), HEK293T cells were transfected with the plasmids encoding for mHLA-B*35/156 or sHLA-B*35/ 156 for production of lentiviral particles. The target cells were transduced with the respective lentivirus encoding for HLAB*35/156 constructs.

Surface expression of mHLA-B*35/156 molecules was analyzed by flow cytometry using the antibodies anti-bw6-FITC and W6/32-PE; data were acquired on a FACS Canto II (Becton Dickinson GmbH, Heidelberg, Germany).

For quantitative verification of sHLA molecules in the supernatant, a double-antibody sandwich (DAS)-ELISA was applied. The mAb W6/32 was used as a capture antibody and a rabbit anti-human $\beta 2 \mathrm{~m}$ pab was utilized as the detection antibody. The clones with the highest expression of sHLA-B*35/ 156 molecules were used for large-scale production.

\section{Large-scale production of sHLA molecules and affinity purification}

sHLA-B35*/156 producing B-LCL cells were expanded in the two-compartment bioreactor CELLine classic 1000. Supernatants were harvested weekly and monitored for sHLA production. sHLA molecules were affinity purified using Nhydroxysuccinimide (NHS)-activated HiTrap columns coupled to $\mathrm{mAb} W 6 / 32$. Affinity purification was performed on the BioLogicDuoFlow system (Bio-Rad, Hercules, USA). Trimeric complexes (class I hc, $\beta_{2} \mathrm{~m}$, and peptide) were eluted using $0.1 \mathrm{M}$ glycine/HCl buffer ( $\mathrm{pH}$ 2.7).

\section{Mass spectrometric analysis of peptides}

Following affinity purification, trimeric complexes were filtered through an Amicon Ultra-15 Filter Unit (EMD Millipore/Merck KgaA, Darmstadt, Germany) with a molecular weight cutoff (MWCO) of $10 \mathrm{kDa}$ and the peptides detected in the flowthrough were considered to be of lowbinding (LB) affinity. The retentate was further acidified by treatment with $0.1 \%$ trifluoroacetic acid (TFA) and filtered through a MWCO 10-kDa filter to elute high-binding (HB) affinity peptides. Subsequently, the peptides were sequenced using an Eksigent Nano-LC Ultra 2D HPLC coupled to LTQ Orbitrap XL mass spectrometer (Thermo Fisher Scientific $\mathrm{GmbH}$, Schwerte, Germany). The mass spectrometric data 
were then utilized on Mascot server via a Mascot Daemon interface (www.matrixscience.com). Database queries for peptide sequences and peptide source were carried out by Mascot software (Hirosawa et al. 1993) using the SwissProt 2012_11 human and the respective decoy databases. UniProtKB/Swiss-Prot 2012_11 release of 28 November 2012 contains 538,585 sequence entries, comprising 191,240,774 AAs abstracted from 215,068 references (http://www.uniprot.org).

\section{Biophysical analysis of HLA-B*35/156 interactions with PLC}

Immunoprecipitation experiments were performed in order to analyze the differential interaction of the HLA-B*35/156 hc and distinct PLC components as previously described (Badrinath et al. 2012). mHLA-B*35/156 expressing LCL 721.220 or LCL 721.221 cells were lysed for $30 \mathrm{~min}$ on ice in Digitonin lysis buffer. The lysates were collected by centrifugation at 13,000 rpm for $15 \mathrm{~min}$ at $4{ }^{\circ} \mathrm{C}$ and pre-cleared with protein A-sepharose beads CL-4B for an hour. The lysates were then added to protein A-sepharose beads covalently coupled to rabbit anti-TAP1 pab to capture and immobilize the immune complex on the beads. The immunoprecipitates were analyzed by western blotting using antibodies against the HLA-B hc and selected PLC components.

\section{Computational analysis}

In order to understand the structural implication of the micropolymorphism at position 156 on HLA-B*35 molecules, a computational simulation was performed to artificially exchange AAs at position 156. The structure of HLA$B * 35: 01$ (2AXG) (Tynan et al. 2005b) was overlaid with that of $B^{*} 35: 08$ (2AXF) (Tynan et al. 2005b), and a model of $B * 35: 62$ was generated by mutation of Leu at 156 $(B * 35: 01,2 A X G)$ to Trp using YASARA/FoldX software.

\section{Results}

\section{Peptide recruitment and biophysical association with the PLC}

Flow cytometric analysis showed differential surface expression of mHLA-B*35/156 molecules on the surface of LCL 721.220 or 721.221 cells. The investigated $B * 35 / 156$ variants were able to load peptides independently of TPN; however, the density of mHLA-B*35/156 molecules on the cell surface is clearly influenced by the type of polymorphism at residue 156. The expression of mHLA-B*35:08 was found to be comparatively low in the absence of TPN compared to HLA$B * 35: 01$ and $B * 35: 62$ (Fig. 1a). These data illustrate that the surface expression of HLA-B*35:08 is relatively more TPN dependent than the surface expression of the other allelic variants investigated. Results demonstrated that the surface expression of mHLA-B*35:62 was relatively more independent of TAP compared to those of mHLA-B*35:01 and B*35:08 (Fig. 1b).

The association of mHLA-B*35/156 molecules and TAP could not be detected in TPN-deficient cells, indicating the significance of TPN in bridging TAP and the HLA molecule. However, a strong association of mHLA-B*35:01 and B*35:08 with TAP was demonstrated in TPN-competent cells. Surprisingly, no such interaction could be detected for mHLAB*35:62 (Fig. 2), indicating its complete PLC-independent mode of peptide loading.

\section{Peptide profiling}

A total of 229,261 , or 492 peptides restricted to sHLAB*35:01, $\mathrm{B} * 35: 08$, or $\mathrm{B} * 35: 62$ are given in Table 1; peptide sequences are given in Supplementary 1. Although an equal concentration of purified sHLA-B*35/156 molecules was utilized for mass spectrometric analysis of the bound peptides, differential numbers of peptides could be recovered due to differential pHLA complex stability among HLA-B*35/156 variants. A comparative analysis of HB and LB peptides facilitates the association of peptide-binding strength and distinct AA exchanges in the HLA hc. The individual profile of peptides acquired in the presence or absence of TPN showed relatively higher numbers of HB peptides for HLA-B*35:01 and $B^{*} 35: 08$ (Fig. 3). In contrast, more LB peptides could be recovered from sHLA-B*35:62 molecules in the presence or absence of TPN.

\section{Shared peptides}

sHLA-B*35/156 variants were expressed in LCL 721.220 or 721.221 cells to ensure that the proteomic content is virtually identical, with the major difference that in 721.220 cells, the peptides are loaded without the assistance of TPN. However, the HLA-B*35/156 allotypes were found to share a very small subset of their overall peptide repertoire, both in the presence and absence of TPN. Shared peptide analysis shows that 11 peptides $(1.12 \%)$ were shared among the HLA-B*35/156 variants (Fig. 4). More peptides were shared in the presence of TPN than in its absence. Among these shared peptides, a 12-mer, ALSTGEKGFGYK (peptidyl-prolylcis-trans isomerase $\mathrm{A}$ ) was acquired in the absence of TPN, while 10 peptides were acquired in the presence of TPN (Fig. 4b, c). The majority of overall shared peptides associated with HLA-B*35:01 or HLA-B*35:08 were HB peptides $(81.81 \%$ for HLA$B * 35: 01$ and $63.63 \%$ for HLA-B*35:08), while only $18.18 \%$ of shared peptides associated with HLA-B*35:62 were found to be HB peptides (Supplementary 2). 
$\mathbf{a}$
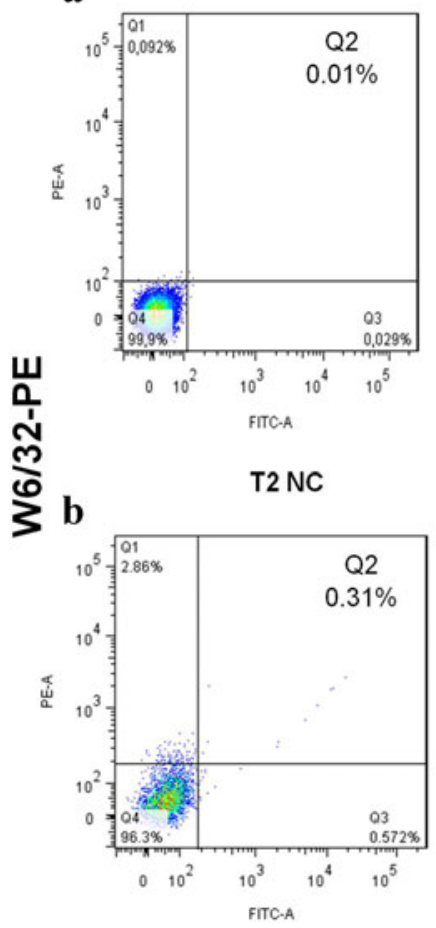

LCL 721.220/ $B^{\star 35: 01156 L e u ~}$

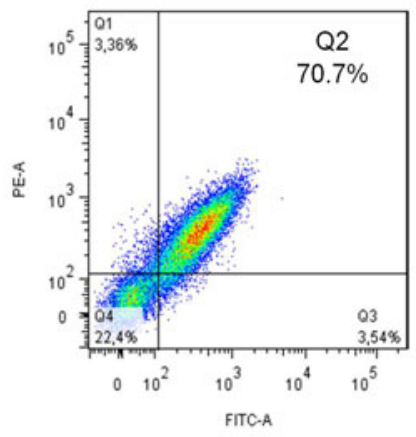

T2 / B*35:01156Leu

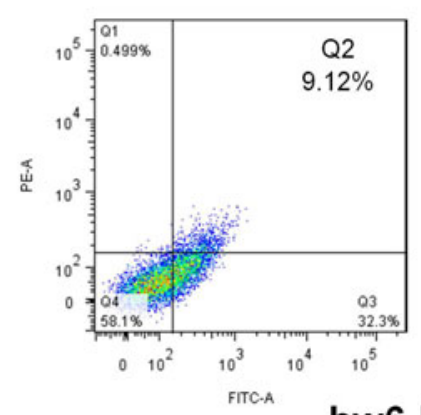

LCL 721.220/ $B^{\star} 35: 08^{156 A r g}$

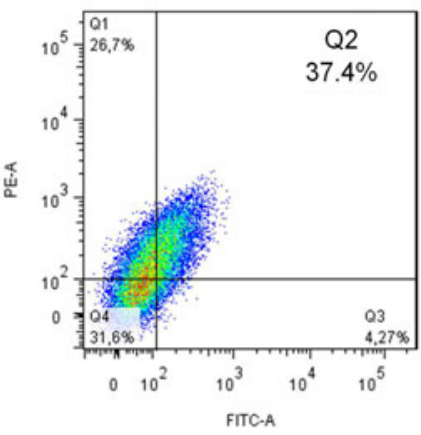

$\mathrm{T} 2 / \mathrm{B}^{\star} 35: 08^{156 \mathrm{Arg}}$

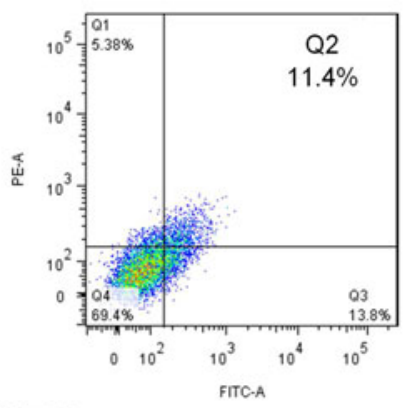

LCL $721.220 / B^{\star} 35: 62^{156 T \text { rp }}$

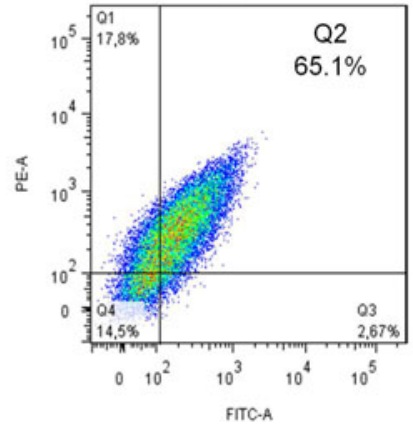

$\mathrm{T} 2 / \mathrm{B}^{\star 35: 62^{156 T \text { TP }}}$

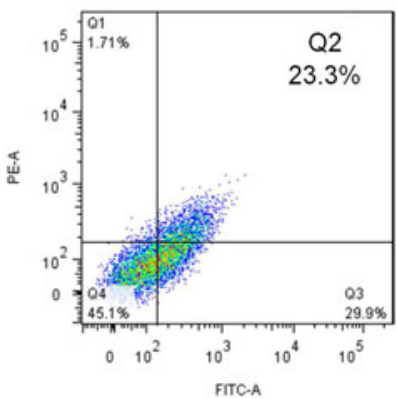

Fig. 1 mHLA-B*35/156 expression. Cells were analyzed for surface expression of mHLA complexes using anti-bw6-FITC and anti-HLA-A/ B/C-PE (W6/32-PE) monoclonal antibodies. a Surface expression of mHLA-B*35/156 variants on LCL $721.220\left(\mathrm{HLA}^{-} / \mathrm{TPN}^{-} / \mathrm{TAP}^{+}\right)$cells. b Surface expression of mHLA-B*35/156 variants on $\mathrm{T} 2\left(\mathrm{HLA}^{-} / \mathrm{TPN}^{+} /\right.$ $\mathrm{TAP}^{-}$) cells. A higher amount of molecules could be detected for mHLA-
$\mathrm{B} * 35: 01$ and $\mathrm{B} * 35: 62$ on LCL 721.220 cells in comparison to the amount of $B * 35: 08$ molecules. Results show relatively higher surface expression of HLA-B*35:62 compared to B*35:01 and B*35:08 on T2 cells, thereby indicating that the surface expression of $\mathrm{B} * 35: 62$ is comparatively more independent of TAP. Annotations: $N C$ negative control (untransduced cells)
Only $3.72 \%$ of the peptides were shared between HLA-B*35:08 and HLA-B*35:62, while $7.77 \%$ were shared between HLA-B*35:01 and $B * 35: 62$. HLA$\mathrm{B} * 35: 01$ and $\mathrm{B} * 35: 08$ share an overall peptide repertoire of $8.78 \%$ (Fig. 4a). Between the three allelic variants, a highly variable peptide repertoire could be observed; it becomes obvious how the differential peptide-loading pathways lead to a divergent selection of the proteomic content. The differential association of the HLA-B*35 allelic variants with the loading complex reflects on the peptide selection. This is highlighted by the numbers of shared peptides given in Fig. 4.

\section{Characteristics of peptide anchor positions}

Analysis of HLA-B*35/156-restricted peptides demonstrated Pro at $\mathrm{p} 2$ (Fig. 5). The preference for Pro at $\mathrm{p} 2$ was decreased for HLA-B*35:01-restricted LB peptides that were acquired in the presence of TPN. HLA-B*35:08 and $B * 35: 62$ were additionally anchored at $\mathrm{p} 2$ by Ala and Val. HLA-B*35:62restricted peptides that were acquired in the absence of TPN were exclusively anchored by Ala at $\mathrm{p} 2$ (Fig. 5a).
At $\mathrm{p} \Omega$, a preference for Tyr, Phe, Leu, or Lys could be observed (Fig. 5). Unlike HLA-B*35:01 and B*35:08, B*35:62 preferentially demonstrated Trp at $\mathrm{p} \Omega$ when acquired in the absence of TPN. Approximately $50 \%$ of sHLA-B*35:62-restricted HB peptides acquired in the absence of TPN exhibited a preference for $\operatorname{Trp}$ at $\mathrm{p} \Omega$ (Supplementary 3). Furthermore, $13.13 \%$ of sHLA-B*35:08-restricted HB peptides acquired in the presence of TPN were preferentially anchored by Met at $\mathrm{p} \Omega$.

\section{Length distribution of peptides}

The majority of sHLA-B*35/156-restricted peptides were found to be of canonical length (8-10 AAs). However, peptides of non-canonical length ( $>10 \mathrm{AAs}$ ) could also be recovered by sHLA-B*35/156 variants (Fig. 6). HLA-B*35:62, in particular, was found to preferentially present peptides of noncanonical length (48.83 and $50.85 \%$ in the absence and presence of TPN, respectively). Among the peptides presented, 31.52 and $31.40 \%$ non-canonical peptides were presented by HLA-B*35:01 and $\mathrm{B} * 35: 08$, respectively, in the absence 


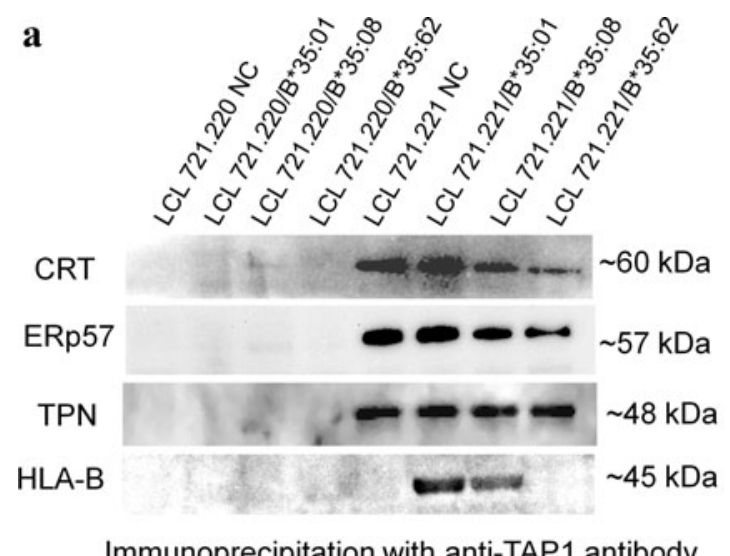

Immunoprecipitation with anti-TAP1 antibody

Fig. 2 Biophysical interaction of mHLA-B*35/156 with PLC components. Cell lysates were used for immunoprecipitation with an anti-TAP1 antibody. Protein-protein interactions were detected with antibodies against HLA-B hc, CRT, ERp57, and TPN. a Detection of CRT, ERp57, TPN, and HLA-B hc in TAP1-precipitates. b Lysate controls showing levels of CRT, ERp57, TPN, and HLA-B hc in

of TPN. In the presence of TPN, HLA-B*35:01 was shown to present $40.15 \%$ non-canonical peptides, while HLA-B*35:08 was shown to present a lesser percentage of longer peptides.

A significant percentage of HB peptides recovered from HLA-B*35:01 or $B^{*} 35: 08$, in the presence of TPN, was found to be of canonical lengths $(71.43 \%$ for HLA-B*35:01 and $80.81 \%$ for HLA-B*35:08); this is in contrast to HLA$\mathrm{B} * 35$ :62-restricted peptides (28\%).

Taken together, in the absence of TPN, both canonical and non-canonical sHLA-B*35/156-restricted HB peptides

Table 1 Profile of peptides

\begin{tabular}{|c|c|c|}
\hline HLA-B*35 allele & HB/LB peptides & Peptides $(N)$ \\
\hline \multirow[t]{2}{*}{ B*35:01 (TPN`) } & LB & 38 \\
\hline & $\mathrm{HB}$ & 54 \\
\hline \multirow[t]{2}{*}{$\mathrm{B} * 35: 01\left(\mathrm{TPN}^{+}\right)$} & LB & 46 \\
\hline & HB & 91 \\
\hline \multirow[t]{2}{*}{$\mathrm{B}^{* 35: 08}\left(\mathrm{TPN}^{-}\right)$} & LB & 33 \\
\hline & HB & 53 \\
\hline \multirow[t]{2}{*}{ B*35:08 $\left(\mathrm{TPN}^{+}\right)$} & LB & 76 \\
\hline & $\mathrm{HB}$ & 99 \\
\hline \multirow[t]{2}{*}{ B*35:62 (TPN') } & LB & 117 \\
\hline & HB & 139 \\
\hline \multirow[t]{2}{*}{ B*35:62 $\left(\mathrm{TPN}^{+}\right)$} & LB & 136 \\
\hline & HB & 100 \\
\hline
\end{tabular}

This table shows the overall profile of $\mathrm{LB}$ or HB peptides

$L B$ low-binding peptides, $H B$ high-binding peptides, $T P N^{+}$acquired in the presence of TPN, TPN acquired in the absence of TPN, $N$ number of peptides

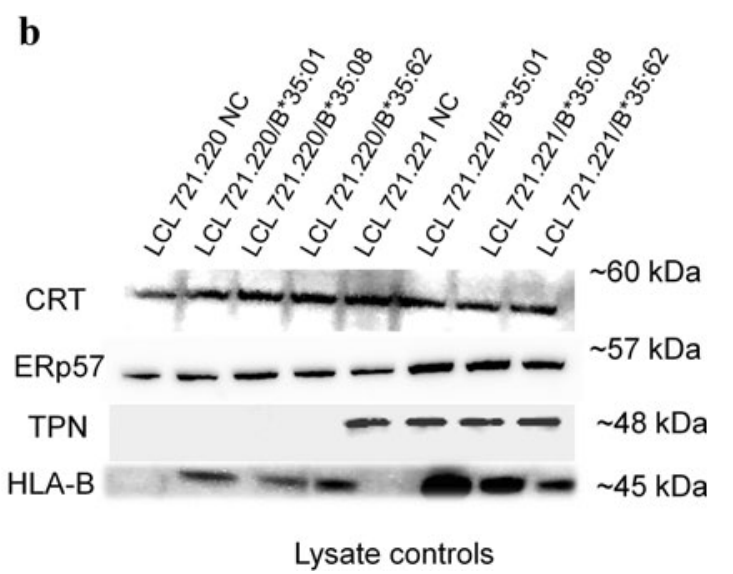

untransduced and transduced LCL 721cells. The presence of essential PLC components in the cells could be verified in the lysate controls. In cells lacking TPN, an interaction between the HLA-B*35/156 hc and TAP was not detected. In TPN-competent cells, hes of HLA-B*35:01 or $\mathrm{B}^{*} 35: 08$ were strongly associated with TAP while no such association could be demonstrated with $\mathrm{B} * 35: 62 \mathrm{hc}$

were observed. The majority of HLA-B*35:01- and $B * 35: 08$-restricted LB peptides were of canonical lengths. Contrary, most of the HLA-B*35:62-restricted LB peptides acquired in the absence of TPN were of non-canonical length $(71.79 \%)$.

\section{Molecular modeling}

sHLA-B*35:62-restricted peptides that were acquired in the absence of TPN are predominantly anchored by a C-terminal Trp. Residue 156 that distinguishes the three allelic variants is not part of pocket $\mathrm{F}$ and thus has no direct influence on the peptide $\mathrm{C}$-terminus. To understand the unexpected alteration of the C-terminal peptide anchor, YASARA/FoldX software was utilized for generating a model of HLA$B * 35: 62$. Crystal structures of HLA-B*35:01 (2AXG) (Tynan et al. 2005b) and B*35:08 (2AXF) (Tynan et al. $2005 b)$ are available and were overlayed. Since no structure of HLA-B*35:62 is available, a model of HLA-B*35:62 was generated by mutating 156Leu in HLA-B*35:01 to 156Trp. In the HLA-B*35:62 model, the stacking arrangement of 147Trp and 156Trp against 97Arg alters the F pocket indirectly and allows for a C-terminal Trp of the bound peptides (Fig. 7).

\section{Discussion}

The degree of donor:recipient HLA-compatibility strongly influences clinical outcome after unrelated stem cell transplantation. Considerable efforts have been made over the last years to distinguish non-permissive HLA mismatches that 
a

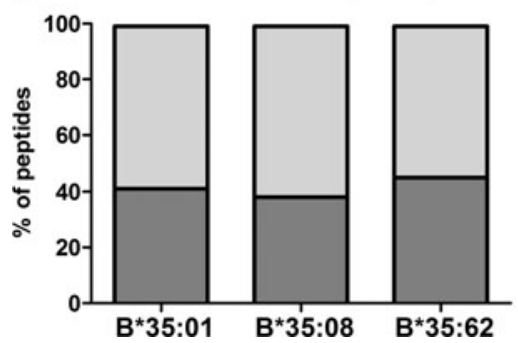

Fig. 3 Differential stability of sHLA-B*35/156 molecules. The $x$ axis represents the HLA-B*35 subtypes, while the $y$ axis represents percentage prevalence of LB and HB peptides. Dark grey represents the LB peptides and light grey the HB peptides. a Analysis of total LB and HB peptides acquired in LCL 721.220 cells. b Analysis of total LB and

\section{b $\quad$ LCL $721.221($ TPN+)}

HB

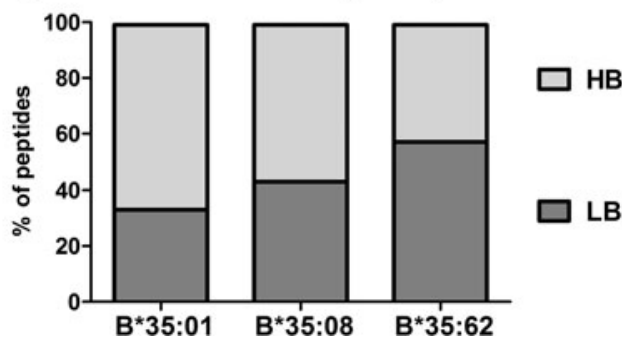

HB peptides acquired in LCL 721.221 cells. sHLA-B*35:62 molecules derived from LCL 721.221 cells showed a higher appearance $(57.63 \%)$ of LB than HB peptides. In contrast, sHLA-B*35:01/35:08 molecules revealed the presentation of comparatively higher percentages of $\mathrm{HB}$ peptides than LB peptides dramatically increase the risk of post-transplantation outcomes from permissive HLA mismatches (Bacigalupo 2013; Flomenberg et al. 2004). Understanding the impact of a particular key polymorphism on the mode of peptide loading, the repertoire of selected and presented peptides, and consequently the alteration in pHLA landscapes and half-life is the prerequisite for the estimation of mismatch allogenicity when no clinical data are available.
Fig. 4 Shared peptides of sHLAB*35/156 variants. a Overall shared peptide repertoire of HLAB*35:01, B*35:08, or B*35:62 restricted peptides. b Shared peptides acquired in the absence of TPN. c Shared peptides acquired in the presence of TPN. A small percentage $(1.12 \%)$ of the overall peptide repertoire was found to be shared between the three different allotypes. Among the pool of peptides, 0.23 and $1.82 \%$ of eluted peptides were shared in the absence and presence of TPN, respectively a

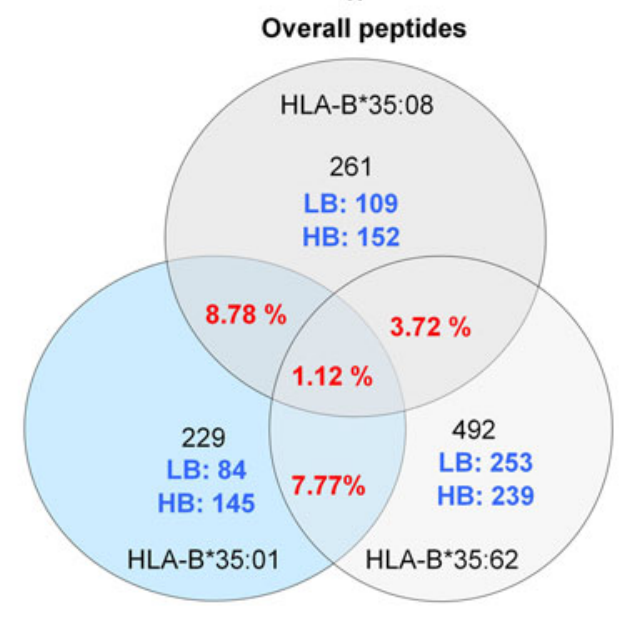

b LCL 721.221 (TPN+)

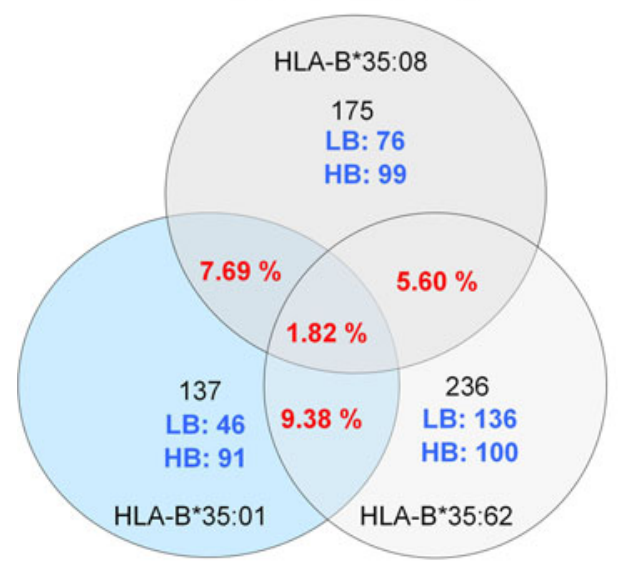

c

LCL 721.220 (TPN-)

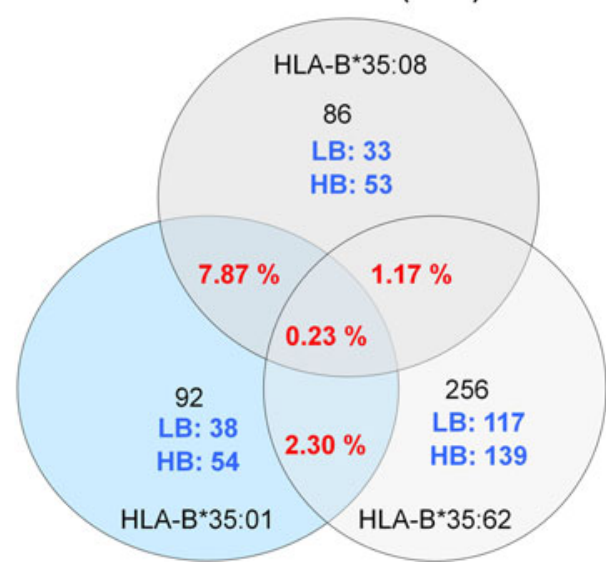


Fig. $5 \mathrm{p} 2$ and $\mathrm{p} \Omega$ anchor positions of sHLA-B*35/156restricted peptides. Characters in red represent the predominant AAs occurring at major anchor position (frequencies $>25 \%$ ). The dots indicate the variable number of AA residues. The graphs on the right panel indicate the frequencies of AAs. The $x$ axis represents the AA residues at $\mathrm{p} 2$ and $\mathrm{p} \Omega$. The $y$ axis represents the percentage prevalence of individual AAs. Black, grey, or crossed bars represent the alleles HLA-B*35:01, B*35:08, or $B * 35: 62$. a Peptide anchor motif in the absence of TPN. $\mathbf{b}$ Peptide anchor motif in the presence of TPN. Pro was the most frequently occurring AA at $\mathrm{p} 2$ position. All HLA-B*35/156 variants are predominantly anchored by Tyr, Phe, Leu, or Lys at $\mathrm{p} \Omega$. However, HLA-B*35:62 is preferentially anchored by Ala at $\mathrm{p} 2$ and Trp at $\mathrm{p}$ $\Omega$ in the absence of TPN
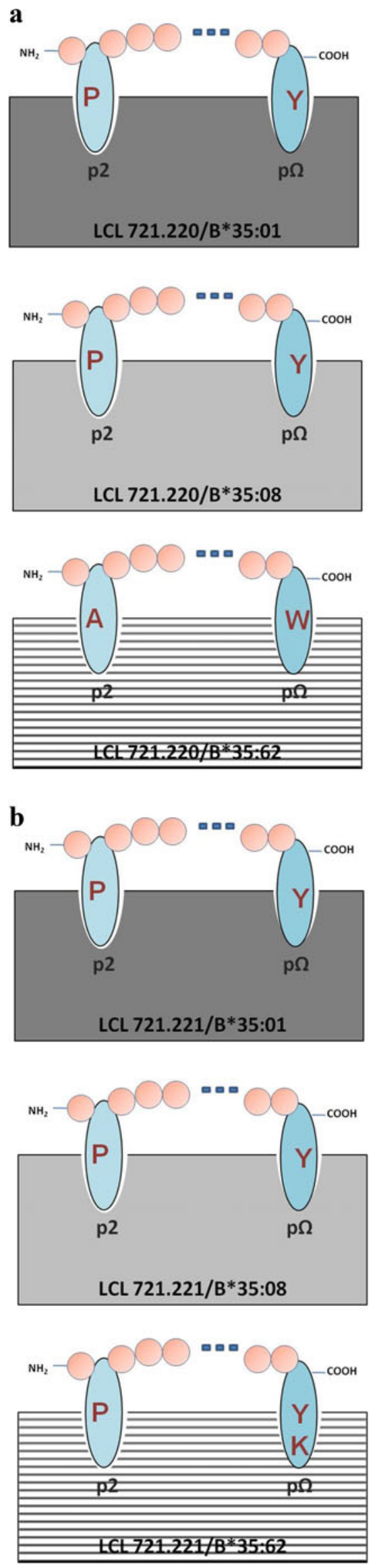

LCL 721.220 (TPN-)

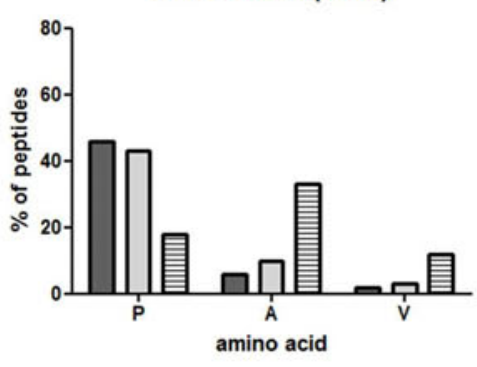

LCL 721.220 (TPN-)

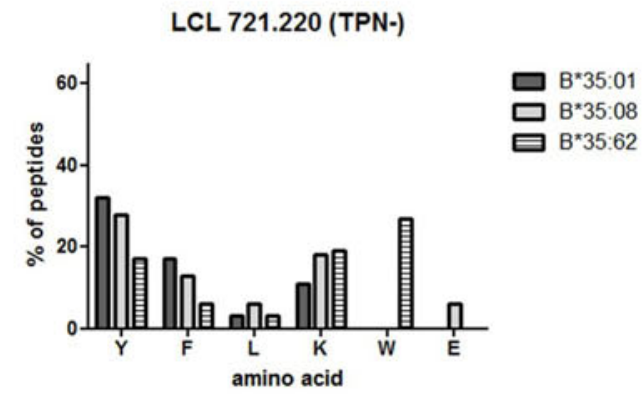

尚*35:01 口*35:08 当 ${ }^{*} 35: 62$

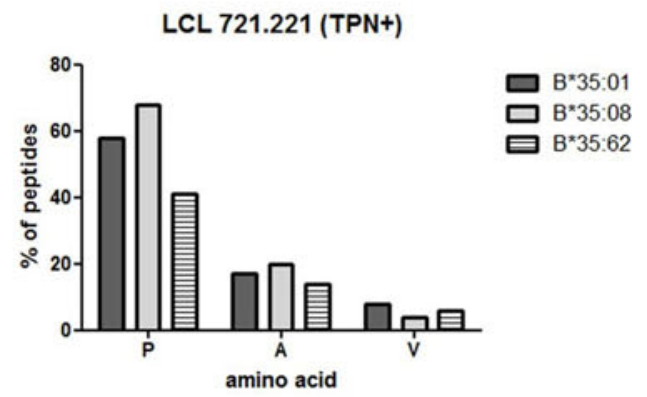

LCL 721.221 (TPN+)

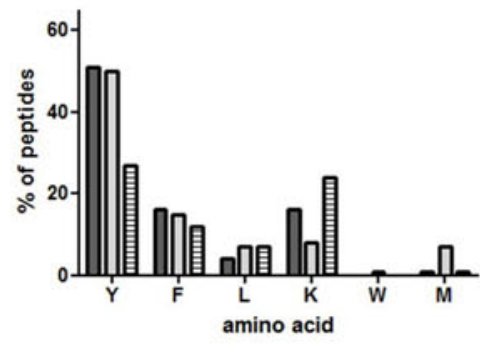

B*35:01

B*35:08 吕*35:62 
a

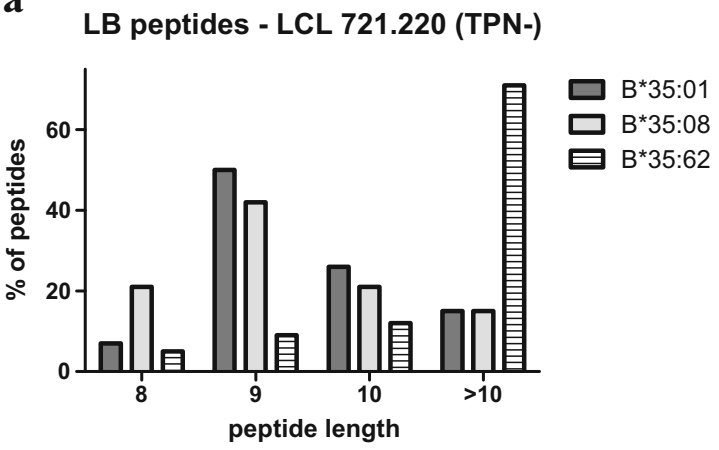

c

HB peptides - LCL 721.220 (TPN-)

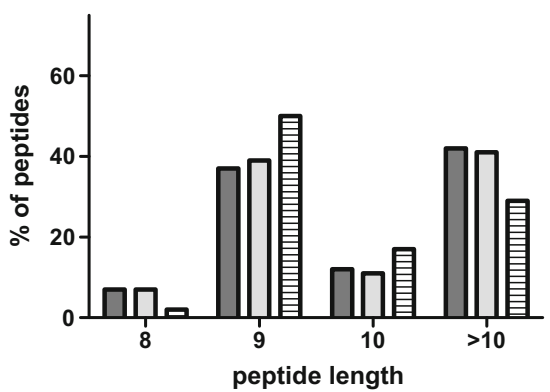

Fig. 6 Length distribution of sHLA-B*35/156-restricted peptides. Peptide length (AA) is given on the $x$ axis, and the percentage prevalence of peptides is given on the $y$ axis. Black, grey, or crossed bars represent the alleles HLA-B*35:01, B*35:08, or B*35:62. a, b Length distribution of LB peptides. $\mathbf{c}$, d Length distribution of HB

The loading of peptides onto HLA class I molecules is a complex procedure and facilitated by the PLC, wherein TAP

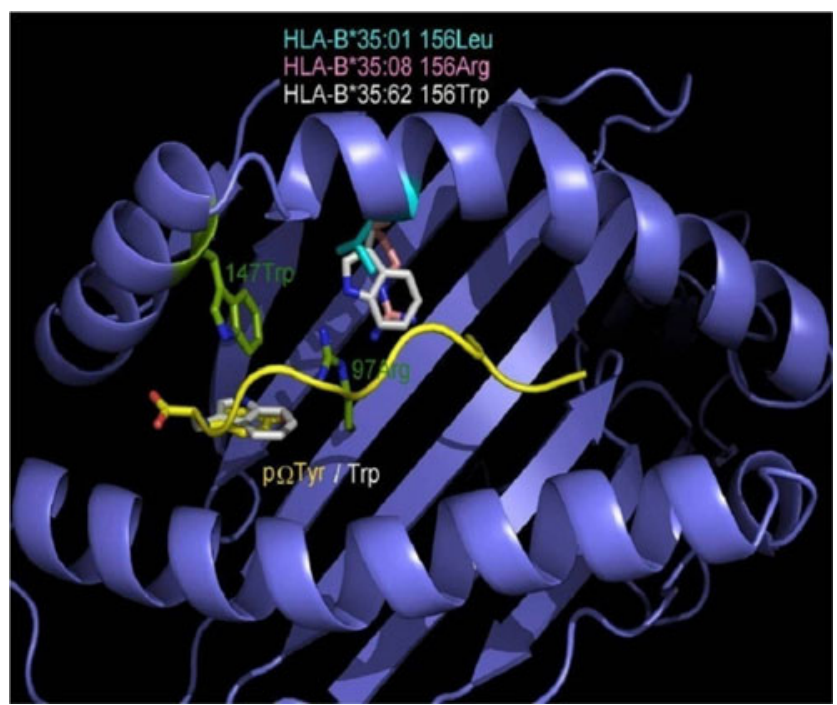

Fig. 7 Model of HLA-B*35:62. Molecular modeling of position 156 in HLA-B*35 utilizing YASARA/FoldX software. Structural overlay of HLA-B*35:01 and $B * 35: 08$ both bound to a decamer peptide (APQPAPENAY) and the modeled structure of HLA-B*35:62. PDB, 2AXG (Tynan et al. 2005b) and 2AXF (Tynan et al. 2005b) b

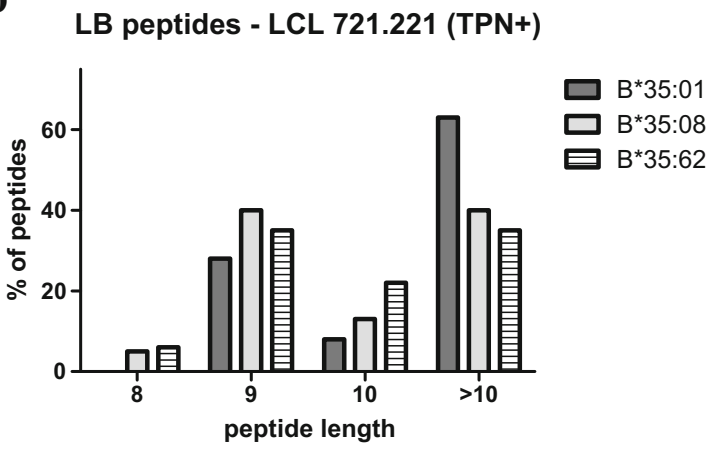

d

HB peptides - LCL 721.221 (TPN+)

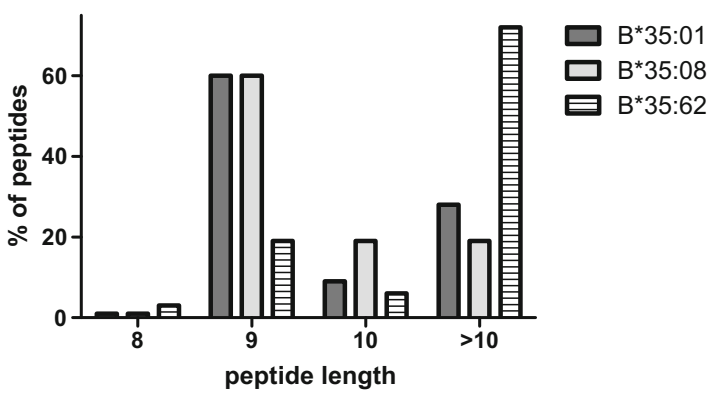

peptides. In the presence of TPN, the majority of HLA-B*35:01- and $B * 35: 08$-restricted HB peptides were of canonical length. HLA$B * 35: 62$-restricted LB peptides that were acquired in the absence of TPN were of non-canonical length

and TPN are essential components. TPN supports peptide loading, stabilizes the TAP complex, and thus indirectly promotes the accessibility of peptides in the ER (Garbi et al. 2003). Furthermore, TPN is known to function in peptide editing and loading of high-affinity peptides (Barnden et al. 2000; Williams et al. 2002). In the absence of TPN, interaction of class I molecules to TAP is disrupted, resulting in unstable pHLA complexes (Peh et al. 2000). Most of the HLA class I molecules rely strictly on the functions of TPN and TAP for efficient peptide loading. Certain viral proteins and cancer proteins target these PLC components to prevent the presentation of immunogenic peptides and recognition by cytotoxic $\mathrm{CD} 8^{+} \mathrm{T}$ cells. Nevertheless, recent studies document host strategies to circumvent these immune evasions by choosing pathways (Boyle et al. 2013; Fromm et al. 2002; Lautscham et al. 2003) that could operate independent of these PLC components. Certain allelic HLA class I variants that load peptides independently from TPN and/or TAP are therefore still able to present a fraction of the intracellular peptide repertoire to the immune system. However, TPN- or TAP-independent peptide presentation might lead to a differential peptide repertoire that would be selected and subsequently presented, since those peptides are not optimized for stabilizing the respective HLA allele. HLA class I variants that are TPN- and/or TAP- 
independent differ from the PLC-dependent alleles often exclusively by one AA difference (Badrinath et al. 2012; Neisig et al. 1996; Williams et al. 2002). Understanding the effect of polymorphism on the immune function of a given HLA molecule can only take the form of a measure of histocompatibility. The similarity of allele peptide-binding profiles and repertoires is such a measure.

HLA-B*35:01 and $\mathrm{B} * 35: 08$ can be distinguished by a micropolymorphism at position 156 ; both variants are described to present viral peptides (Liu et al. 2014; Tynan et al. 2005a, 2007; Wynn et al. 2008), suggesting a PLC independency for these allelic variants. This study was focused on determining the mode of antigen recruitment utilized by natural occurring HLA-B*35 allotypes that differ at one single mismatch at residue 156, HLA-B*35:01 ${ }^{156 \mathrm{Leu}}, \mathrm{B} * 35: 08^{156 \mathrm{Arg}}$, and $\mathrm{B} * 35: 62^{156 \operatorname{Trp}}$.

All three HLA-B*35/156 variants studied were expressed on the cell surface of TPN-deficient cells, suggesting a TPNindependent mode of peptide acquisition and presentation for these molecules. However, the spectrum of TPN dependence among these allotypes was found to vary with the nature of AA at position 156. The data revealed the influence of microploymorphism at position 156 on the molecule expression levels and stability of pHLA complexes on the cell surface. A recent study by Rizvi et al. (2014) also demonstrated a TPN-independent mode of peptide loading for HLA-B*35:01. The 156 micropolymorphism distinguishing the HLA-B*35/156 allotypes causes a functional disparity for their TPN interaction. Unlike HLA-B*35:01 ${ }^{156 \text { Leu }}$ and $B * 35: 62^{156 \mathrm{Trp}}$, surface expression of $\mathrm{B} * 35: 08^{156 \mathrm{Arg}}$ was decreased by more than twofold in the absence of TPN, indicating partial dependence of $\mathrm{B} * 35: 08$ on TPN for peptide loading and presentation. In addition to TPN independence, our results showed that the surface expression of HLA-B*35:62 was relatively independent of TAP compared to that of HLA$B * 35: 01$ and $B * 35: 08$.

Immunoprecipitation experiments demonstrated differential association of TAP with the HLA-B*35:01 $1^{156 \text { Leu }}$ hc, B*35:08 ${ }^{156 \mathrm{Arg}}$ hc, or the B*35:62 ${ }^{156 \operatorname{Trp}}$ hc. The HLA-B*35/ $156 \mathrm{hc}$ could not be detected in any of the TAP complexes from cells lacking TPN (LCL 721.220 cells), since the association between TAP and the HLA hc is mediated through TPN. TPN plays an important role in steady state expression of TAP (Lehner et al. 1998) and also helps in the stabilization of the heterodimeric TAP1/TAP2 complex. In contrast, in TPN positive cells (LCL 721.221), a strong association of both HLA-B*35:01 he and HLA-B*35:08 he with TAP could be detected. The observations validate the accepted role of TPN in bridging a HLA class I molecule and the TAP complex (Ortmann et al. 1997; Sadasivan et al. 1996). However, unlike HLA-B*35:01 and $B * 35: 08$, the association of the $B * 35: 62$ hc with TAP could not be confirmed. This result could mean that either HLA-B*35:62 does not incorporate into the PLC and does not utilize the TAP complex for peptide loading or the transit period of HLA-B*35:62 into the PLC is so concise that the interaction could not be detected using this experimental approach.

The results from the immunoprecipitation experiments were in synchrony with the flow cytometric studies where the surface expression of HLA-B*35:62 was found to be comparatively independent of TAP. The observed results could be suggestive that HLA-B*35:62 might be very weakly or not at all associated with TAP. The findings postulate the involvement of an unknown alternate pathway for peptide selection and presentation by HLA-B*35:62. Given that all the three HLA-B*35/156 variants share the same AA sequence except for the single AA polymorphism at position 156, Trp156 in HLA-B*35:62 would be the most likely factor regulating the association of this allele with TAP and modulating a differential mode of peptide loading. Several studies revealed how certain allelic variants that differ at one or more AAs might vary in their TAP association. HLA-B*44:02 ${ }^{116 \text { Asp/156Asp }}$ which differs from HLA-B*44:03 ${ }^{116 \mathrm{Asp} / 156 \mathrm{Leu}}$ by a single AA at position 156 and from HLA-B*44:05 ${ }^{116 \mathrm{Tyr} / 156 \mathrm{Asp}}$ at position 116 bounds strongly to TAP, while HLAB*44:03 ${ }^{116 \mathrm{Asp} / 156 \mathrm{Leu}}$ (Neisig et al. 1996) and HLA$\mathrm{B}^{*} 44: 05^{116 \mathrm{Tyr} / 156 \mathrm{Asp}}$ (Zernich et al. 2004) did not. It was demonstrated that HLA-A*68:07 $7^{116 \mathrm{His} / 70 \mathrm{Gln}}$ is associated much stronger with TAP than HLA-A*68:03 ${ }^{116 A s p / 70 H i s}$ (Turnquist et al. 2002). In 1996, Neisig et al. (1996) demonstrated that HLA-B alleles with aromatic AAs at position 116 could be a better TAP binder compared to the others. It was observed that among the HLA-B*15 allotypes, HLA-B* $15: 10^{116 \mathrm{Tyr}}$ showed a stronger association with TAP compared to HLA$\mathrm{B}^{*} 15: 18^{116 \mathrm{Ser}}$ (Turnquist et al. 2000). In case of HLA$\mathrm{B}^{*} 35: 62^{156 \mathrm{Tr}}$, it is possible that Trp at position 156 alters the overall conformation of the PBR sufficiently to affect its interaction with neighboring AA residues, thereby rendering a TAP-independent mode of peptide loading.

To analyze if the polymorphic difference at position 156 alters the peptide-binding specificities, soluble HLA technology (Bade-Doeding et al. 2004; Kunze-Schumacher et al. 2014) was utilized to characterize the repertoire of peptides presented by HLA-B*35:01 $1^{156 \mathrm{Leu}}, \mathrm{B} * 35: 08^{156 \mathrm{Arg}}$, and $B * 35: 62^{156 \text { Trp }}$. In the present study, it could be demonstrated how a single mismatch at residue 156 in HLA-B*35/156 allotypes changes the peptide-binding groove sufficiently to alter the features of the selected peptide repertoire.

Position $\mathrm{p} 2$ and the $\mathrm{C}$-terminal position $\mathrm{p} \Omega$ of a peptide are significant for an effective binding in the PBR of most allotypes (Falk et al. 1991; Parker et al. 1992) and thus determine allelic specificity. Hence, the HLA-B*35/156-bound peptides were investigated for the peptide-binding anchor motifs at $\mathrm{p} 2$ and $\mathrm{p} \Omega$. The results demonstrated similar peptide-binding preferences for HLA-B*35:01 and B*35:08; however, HLA$B * 35: 62$ showed striking differences for the anchor motif at 
$\mathrm{p} 2$ and $\mathrm{p} \Omega$, especially in TPN-deficient cells. The mass spectrometric analysis revealed that HLA-B*35:01- and B*35:08restricted peptides acquired in the presence or absence of TPN are preferentially $\mathrm{N}$-terminal anchored by Pro at $\mathrm{p} 2$. The preference for Pro at $\mathrm{p} 2$ for HLA-B*35:01 and $\mathrm{B} * 35: 08$ is consistent with previous studies (Escobar et al. 2008; Falk et al. 1993; Sidney et al. 1995; Steinle et al. 1995). In contrast, surprisingly, the binding motif of HLA-B*35:62 showed an unusual preference for Ala at $\mathrm{p} 2$, in the absence of TPN. Comparison of AA frequencies in peptides derived from sHLA-B*35/156 showed a preference of Tyr, Phe, Leu, or Lys at $\mathrm{p} \Omega$. Unlike HLA-B*35:01 and $B * 35: 08, B * 35: 62$ preferentially binds peptides with $\operatorname{Trp}$ at $\mathrm{p} \Omega$ in the absence of TPN. These results imply the influence of Trp at position 156 in HLA-B*35:62 on alteration of peptide selectivity by TPN. To validate the possible structural implication of position 156 on HLA-B*35:62 molecule, a structural model of HLA-B*35:62 was generated by mutating Leu at position 156 in the HLA-B*35:01 structure (2AXG) (Tynan et al. $2005 b)$ to Trp. This mutational model of HLA-B*35.62 revealed a stacking arrangement of 147Trp and 156Trp against 97Arg. The residue triad, $147 \mathrm{Trp} / 156 \operatorname{Trp} / 97 \mathrm{Arg}$, was found to be highly selective for a C-terminal Trp of the bound peptide. It was also demonstrated that HLA-B*35/156 variants were able to present peptides of non-canonical lengths ( $>10 \mathrm{AAs}$ ). Generally, it was considered that HLA class I molecules present peptides of canonical length (8-10 AAs). The limit for peptide length restriction depends, in part, by structure and conformation of PBR. It was reported that peptides of noncanonical length could be bound by HLA-B*35:01 and $B * 35: 08$ molecules and such peptides can be highly immunogenic (Green et al. 2004; Probst-Kepper et al. 2004; Tynan et al. 2005a).

Furthermore, to understand if the micropolymorphism at position 156 would impact the stability of pHLA complexes, peptide binding affinities, as reflected by profiles of LB and HB peptides, were analyzed and correlated with the results of flow cytometry and immunoprecipitation experiments. Analysis of peptides presented by HLA-B*35:01 and B*35:08 molecules in the presence of TPN (LCL 721.221 cells) displayed the majority of them being HB peptides. It was expected that the absence of TPN would lead to the presentation of a higher quantity of LB peptides. However, no significant differences between the percentages of HB and LB peptides were observed from peptides presented by these alleles in the absence of TPN. Especially, it was expected that HLA$B * 35: 08$, which was found to be relatively more dependent on TPN for surface expression, would present peptides of low affinity in the absence of TPN. Our findings suggests that the probable dependence of HLA-B*35:08 on TPN is on egress of pHLA complex from ER to cell surface and their stabilization on cell surface rather than inside the cell. The results could be comparable to the findings observed in peptides associated with HLA-B*08:01 and HLA-A*02:01, where the peptides acquired in absence of TPN were found to be of unexpected higher affinity than those acquired in its presence (Zarling et al. 2003). Moreover, Raghuraman et al. (2002), using an insect cell-reconstituted system and peptide translocation assay, observed that TPN does not alter the peptide translocation efficiency and presence of TPN unexpectedly slightly reduced the affinity of TAP complexes for peptides, suggesting that TPN is less likely to alter the peptide selectivity by TAP and hence the features of TAPtranslocatable peptides. These results indicated the role of TPN in stabilizing a peptide receptive conformation of the PBR but not to function as a peptide editor to discriminate between low- and high-binding peptides. Furthermore, a peptide receptive conformation of the PBR may not always mean the conformation of HLA molecule with HB affinity or tightly bound peptides.

Beside this, HLA-B*35:62 was shown to present a higher percentage of LB peptides in the presence of TPN that could be indirectly attributed to its TAP-independent character. The selectivity of TAP is important because it helps in peptide selection by translocation of peptides of optimal length and sequence to their corresponding HLA class I molecules (Momburg et al. 1994a, b). Our experimental data revealed that HLA-B*35:62 could acquire peptides independent of TAP. It is most likely that TAP is not being utilized for selection of HLA-B*35:62-specific peptides; therefore poorly selected peptides are presented by $B * 35: 62$ even in the presence of TPN. All these observations imply that the AA mismatch at position 156 in HLA-B*35 variants has the potential to alter the stability of these pHLA complexes and influence the mode by which TPN or TAP functions.

The peptide-binding characteristics of individual HLA class I proteins are shown to be a major factor determining the immunorecognition of pathogens (Pereyra et al. 2010) and the findings for these HLA-B*35/156 alleles indicate a probable role in the presentation of viral epitopes. Moreover, refolding assays on conformational stabilities have shown that TPN-independent allotypes were found to be more assembly competent and are in a more stable peptide-receptive conformation compared with TPN-dependent allotypes (Geironson et al. 2013; Rizvi et al. 2014). This result highlighted the added advantage of these TPN-independent alleles for pathogen recognition. Paradoxically, dependence of individual HLA class I molecules on TPN can influence the assembly and stability of individual HLA class I molecules and have a subsequent impact on disease progression (Rizvi et al. 2014).

Moreover, the presence of Trp at position 156 in HLAB*35:62 was shown to confer a TAP-independent mode of peptide loading that could be suggestive of conferring the ability of peptide presentation via non-classical pathways and its potential role in immune response against viral infections. However, such differences on the mode of peptide 
loading can have interference on the alliance with ER quality control factors, stabilities of antigenic peptide associations with HLA-B molecules, and hence the abilities of HLA-B molecules to mediate immune responses during infections. HLA-B*35:62 is a rare allele occurring sparsely in Hispanic population (http://www.allelefrequencies.net; http://www.ebi. ac.uk) and further studies are needed to better understand the reason for its failure to be selected in the course of hostpathogen co-evolution.

Our study highlights how a single AA mismatch at position 156 orchestrates the mode of peptide loading and repertoire of presented peptides. This study as a whole is a part of our continual effort to provide better explanation and estimation of outcomes of HLA mismatches through biochemical and structural analyses of key polymorphic position in HLA alleles. These results will direct toward intelligent mismatching strategies and guide toward personalized treatment of viral infections.

Open Access This article is distributed under the terms of the Creative Commons Attribution 4.0 International License (http:// creativecommons.org/licenses/by/4.0/), which permits unrestricted use, distribution, and reproduction in any medium, provided you give appropriate credit to the original author(s) and the source, provide a link to the Creative Commons license, and indicate if changes were made.

\section{References}

Ackerman AL, Cresswell P (2004) Cellular mechanisms governing crosspresentation of exogenous antigens. Nat Immunol 5:678-684

Bacigalupo A (2013) A closer look at permissive HLA mismatch. Blood 122:3555-3556. doi:10.1182/blood-2013-09-525469

Bade-Doeding C, Elsner H-A, Eiz-Vesper B, Seltsam A, Holtkamp U, Blasczyk R (2004) A single amino-acid polymorphism in pocket A of HLA-A*6602 alters the auxiliary anchors compared with HLAA*6601 ligands. Immunogenetics 56:83-88

Badrinath S, Saunders P, Huyton T, Aufderbeck S, Hiller O, Blasczyk R, Bade-Doeding C (2012) Position 156 influences the peptide repertoire and tapasin dependency of human leukocyte antigen $\mathrm{B}^{*} 44$ allotypes. Haematologica 97:98-106

Badrinath S, Huyton T, K-S H, Elsner HA, Blasczyk R (2014) Differential impact of HLA-B*44 allelic mismatches at position 156 on peptide binding specificities and T-cell diversity. Jounal of Stem Cell Research and Therapy 4

Barnden MJ, Purcell AW, Gorman JJ, McCluskey J (2000) Tapasinmediated retention and optimization of peptide ligands during the assembly of class I molecules. J Immunol 165:322-330

Blazar BR, Murphy WJ, Abedi M (2012) Advances in graft-versus-host disease biology and therapy. Nat Rev Immunol 12:443-458

Boyle LH, Hermann C, Boname JM, Porter KM, Patel PA, Burr ML, Duncan LM, Harbour ME, Rhodes DA, Skjødt K, Lehner PJ, Trowsdale J (2013) Tapasin-related protein TAPBPR is an additional component of the MHC class I presentation pathway. Proc Natl Acad Sci 110:3465-3470. doi:10.1073/pnas.1222342110

Burrows JM, Wynn KK, Tynan FE, Archbold J, Miles JJ, Bell MJ, Brennan RM, Walker S, McCluskey J, Rossjohn J, Khanna R, Burrows SR (2007) The impact of HLA-B micropolymorphism outside primary peptide anchor pockets on the CTL response to CMV. Eur J Immunol 37:946-953

Dick TP, Bangia N, Peaper DR, Cresswell P (2002) Disulfide bond isomerization and the assembly of MHC class I-peptide complexes. Immunity 16:87-98

Elliott T, Williams A (2005) The optimization of peptide cargo bound to MHC class I molecules by the peptide-loading complex. Immunol Rev 207:89-99

Escobar H, Crockett DK, Reyes-Vargas E, Baena A, Rockwood AL, Jensen PE, Delgado JC (2008) Large scale mass spectrometric profiling of peptides eluted from HLA molecules reveals N-terminalextended peptide motifs. J Immunol 181:4874-4882

Falk K, Rotzschke O, Stevanovie S, Jung G, Rammensee H-G (1991) Allele-specific motifs revealed by sequencing of self-peptides eluted from MHC molecules. Nature 351:290-296

Falk K, Rotzschke O, Grahovac B, Schendel D, Stevanovic S, Jung G, Rammensee HG (1993) Peptide motifs of HLA-B35 and -B37 molecules. Immunogenetics 38:161-162

Fleischhauer K, Kernan NA, O'Reilly RJ, Dupont B, Yang SY (1990) Bone marrow-allograft rejection by $\mathrm{T}$ lymphocytes recognizing a single amino acid difference in HLA-B44. N Engl J Med 323: 1818-1822. doi:10.1056/NEJM199012273232607

Fleischhauer K, Avila D, Vilbois F, Traversari C, Bordignon C, Wallny HJ (1994) Characterization of natural peptide ligands for HLA$B * 4402$ and $-\mathrm{B} * 4403$ : implications for peptide involvement in allorecognition of a single amino acid change in the HLA-B44 heavy chain. Tissue Antigens 44:311-317

Flomenberg N, Baxter-Lowe LA, Confer D, Fernandez-Vina M, Filipovich A, Horowitz M, Hurley C, Kollman C, Anasetti C, Noreen H, Begovich A, Hildebrand W, Petersdorf E, Schmeckpeper B, Setterholm M, Trachtenberg E, Williams T, Yunis E, Weisdorf D (2004) Impact of HLA class I and class II high-resolution matching on outcomes of unrelated donor bone marrow transplantation: HLA-C mismatching is associated with a strong adverse effect on transplantation outcome. Blood 104:1923-1930. doi:10.1182/blood-2004-03-0803

Fromm SV, Duady-Ben Yaakov S, Schechter C, Ehrlich R (2002) Assembly and cell surface expression of TAP-independent, chloroquine-sensitive and interferon-gamma-inducible class I MHC complexes in transformed fibroblast cell lines are regulated by tapasin. Cell Immunol 215:207-218

Garbi N, Tiwari N, Momburg F, Hämmerling GJ (2003) A major role for tapasin as a stabilizer of the TAP peptide transporter and consequences for MHC class I expression. Eur J Immunol 33:264-273

Gavin MA, Gilbert MJ, Riddell SR, Greenberg PD, Bevan MJ (1993) Alkali hydrolysis of recombinant proteins allows for the rapid identification of class I MHC-restricted CTL epitopes. J Immunol 151: 3971-3980

Geironson L, Thuring C, Harndahl M, Rasmussen M, Sr B, Røder G, Paulsson KM (2013) Tapasin facilitation of natural HLA-A and -B allomorphs is strongly influenced by peptide length, depends on stability, and separates closely related allomorphs. J Immunol 191: 3939-3947. doi:10.4049/jimmunol.1201741

Goker H, Haznedaroglu IC, Chao NJ (2001) Acute graft-vs-host disease: pathobiology and management. Exp Hematol 29:259-277

Green KJ, Miles JJ, Tellam J, van Zuylen WJM, Connolly G, Burrows SR (2004) Potent T cell response to a class I-binding 13-mer viral epitope and the influence of HLA micropolymorphism in controlling epitope length. Eur J Immunol 34:2510-2519. doi:10.1002/eji. 200425193

Hauzenberger D, Schaffer M, Ringdén O, Hassan Z, Omazic B, Mattsson J, Wikström AC, Remberger M (2008) Outcome of haematopoietic stem cell transplantation in patients transplanted with matched unrelated donors vs allele-mismatched donors: a single centre study. Tissue Antigens 72:549-558 
Hirosawa M, Hoshida M, Ishikawa M, Toya T (1993) MASCOT: multiple alignment system for protein sequences based on three-way dynamic programming. Comput Appl Biosci 9:161-167

Keever CA, Leong N, Cunningham I, Copelan EA, Avalos BR, Klein J, Kapoor N, Adams PW, Orosz CG, Tutschka PJ (1994) HLA-B44directed cytotoxic $\mathrm{T}$ cells associated with acute graft-versus-host disease following unrelated bone marrow transplantation. Bone Marrow Transplant 14:137-145

Kunze-Schumacher H, Blasczyk R, Bade-Doeding C (2014) Soluble HLA technology as a strategy to evaluate the impact allogenicity of HLA mismatches. Int J Immunol Res

Lautscham G, Rickinson A, Blake N (2003) TAP-independent antigen presentation on MHC class I molecules: lessons from Epstein-Barr virus. Microbes Infect 5:291-299

Lehner PJ, Surman MJ, Cresswell P (1998) Soluble tapasin restores MHC class I expression and function in the tapasin-negative cell line.220. Immunity 8:221-231

Liu YC, Chen Z, Neller MA, Miles JJ, Purcell AW, McCluskey J, Burrows SR, Rossjohn J, Gras S (2014) A molecular basis for the interplay between $\mathrm{T}$ cells, viral mutants and human leukocyte antigen micropolymorphism. J Biol Chem 289:16688-16698. doi:10. 1074/jbc.M114.563502

Marsh S, Parham P, Barber L (2000) The HLA facts book. London Academic Press, London

McAulay KA, Haque T, Urquhart G, Bellamy C, Guiretti D, Crawford DH (2009) Epitope specificity and clonality of EBV-specific CTLs used to treat posttransplant lymphoproliferative disease. J Immunol 182:3892-3901

Momburg F, Neefjes JJ, Hammerling GJ (1994a) Peptide selection by MHC-encoded TAP transporters. Curr Opin Immunol 6:32-37

Momburg F, Roelse J, Hammerling GJ, Neefjes JJ (1994b) Peptide size selection by the major histocompatibility complex-encoded peptide transporter. J Exp Med 179:1613-1623

Neisig A, Wubbolts R, Zang X, Melief C, Neefjes J (1996) Allele-specific differences in the interaction of MHC class I molecules with transporters associated with antigen processing. J Immunol 156:3196-3206

Ortmann B, Copeman J, Lehner PJ, Sadasivan B, Herberg JA, Grandea AG, Riddell SR, Tampé R, Spies T, Trowsdale J, Cresswell P (1997) A critical role for tapasin in the assembly and function of multimeric MHC class I-TAP complexes. Science 277:1306-1309. doi:10. $1126 /$ science. 277.5330 .1306

Park B, Lee S, Kim E, Ahn K (2003) A single polymorphic residue within the peptide-binding cleft of MHC class I molecules determines spectrum of tapasin dependence. J Immunol 170:961-968

Park B, Kim Y, Shin J, Lee S, Cho K, Früh K, Lee S, Ahn K (2004) Human cytomegalovirus inhibits tapasin-dependent peptide loading and optimization of the MHC class I peptide cargo for immune evasion. Immunity 20:71-85

Parker KC, Bednarek MA, Hull LK, Utz U, Cunningham B, Zweerink HJ, Biddison WE, Coligan JE (1992) Sequence motifs important for peptide binding to the human MHC class I molecule, HLA-A2. J Immunol 149:3580-3587

Peh CA, Laham N, Burrows SR, Zhu Y, McCluskey J (2000) Distinct functions of tapasin revealed by polymorphism in MHC class I peptide loading. J Immunol 164:292-299

Pereyra F, Jia X, McLaren PJ (2010) The major genetic determinants of HIV-1 control affect HLA class I peptide presentation. Science 330: $1551-1557$

Pidala J, Wang T, Haagenson M, Spellman SR, Askar M, Battiwalla M, Baxter-Lowe LA, Bitan M, Fernandez-Viña M, Gandhi M, Jakubowski AA, Maiers M, Marino SR, Marsh SGE, Oudshoorn M, Palmer J, Prasad VK, Reddy V, Ringden O, Saber W, Santarone S, Schultz KR, Setterholm M, Trachtenberg E, Turner EV, Woolfrey AE, Lee SJ, Anasetti C (2013) Amino acid substitution at peptidebinding pockets of HLA class I molecules increases risk of severe acute GVHD and mortality. Blood 122:3651-3658. doi:10.1182/ blood-2013-05-501510

Probst-Kepper M, Hecht H-J, Herrmann H, Janke V, Ocklenburg F, Klempnauer J, van den Eynde BJ, Weiss S (2004) Conformational restraints and flexibility of 14-meric peptides in complex with HLAB*3501. J Immunol 173:5610-5616

Raghuraman G, Lapinski PE, Raghavan M (2002) Tapasin Interacts with the membrane-spanning domains of both TAP subunits and enhances the structural stability of TAP1 - TAP2 complexes. J Biol Chem 277:41786-41794. doi:10.1074/jbc.M207128200

Ragupathi G, Cereb N, Yang SY (1995) The relative distribution of B35 alleles and their IEF isotypes in a HLA-B35-positive population. Tissue Antigens 46:24-31

Rickinson AB, Moss DJ (1997) Human cytotoxic T lymphocytes responses to Epstein-Barr virus infection. Annu Rev Immunol 15: 405-431. doi:10.1146/annurev.immunol.15.1.405

Rizvi SM, Salam N, Geng J, Qi Y, Bream JH, Duggal P, Hussain SK, Martinson J, Wolinsky SM, Carrington M, Raghavan M (2014) Distinct assembly profiles of HLA-B molecules. J Immunol 192: 4967-4976. doi:10.4049/jimmunol.1301670

Robinson J, Halliwell JA, Hayhurst JD, Flicek P, Parham P, Marsh SG (2015) The IPD and IMGT/HLA database: allele variant databases. Nucleic Acids Res 43:D423-D431. doi:10.1093/nar/gku1161

Sadasivan B, Lehner PJ, Ortmann B, Spies T, Cresswell P (1996) Roles for calreticulin and a novel glycoprotein, tapasin, in the interaction of MHC class I molecules with TAP. Immunity 5:103-114

Shaw BE (2008) The clinical implications of HLA mismatches in unrelated donor haematopoietic cell transplantation. Int J Immunogenet 35:367-374

Sidney J, del Guercio MF, Southwood S, Engelhard VH, Appella E, Rammensee HG, Falk K, Rötzschke O, Takiguchi M, Kubo RT (1995) Several HLA alleles share overlapping peptide specificities. J Immunol 154:247-259

Steinle A, Falk K, Rötzschke O, Gnau V, StevanoviÄ $\$$ S, Jung G, Schendel D, Rammensee H-G (1995) Motif of HLA-B*3503 peptide ligands. Immunogenetics 43:105-107

Turnquist HR, Thomas HJ, Prilliman KR, Lutz CT, Hildebrand WH, Solheim JC (2000) HLA-B polymorphism affects interactions with multiple endoplasmic reticulum proteins. Eur J Immunol 30: 3021-3028

Turnquist H, Vargas S, Schenk E, McIlhaney M, Reber A, Solheim J (2002) The interface between tapasin and MHC class I. Immunol Res 25:261-269

Tynan FE, Borg NA, Miles JJ, Beddoe T, El-Hassen D, Silins SL, van Zuylen WJM, Purcell AW, Kjer-Nielsen L, McCluskey J, Burrows SR, Rossjohn J (2005a) High resolution structures of highly bulged viral epitopes bound to major histocompatibility complex class I: implications for T-cell receptor engagement and T-cell immunodominance. J Biol Chem 280:23900-23909. doi:10.1074/ jbc.M503060200

Tynan FE, Elhassen D, Purcell AW, Burrows JM, Borg NA, Miles JJ, Williamson NA, Green KJ, Tellam J, Kjer-Nielsen L, McCluskey J, Rossjohn J, Burrows SR (2005b) The immunogenicity of a viral cytotoxic T cell epitope is controlled by its MHC-bound conformation. J Exp Med 202:1249-1260. doi:10.1084/jem.20050864

Tynan FE, Reid HH, Kjer-Nielsen L, Miles JJ, Wilce MCJ, Kostenko L, Borg NA, Williamson NA, Beddoe T, Purcell AW, Burrows SR, McCluskey J, Rossjohn J (2007) A T cell receptor flattens a bulged antigenic peptide presented by a major histocompatibility complex class I molecule. Nat Immunol 8:268-276

Wearsch PA, Cresswell P (2007) Selective loading of high-affinity peptides onto major histocompatibility complex class I molecules by the tapasin-ERp57 heterodimer. Nat Immunol 8:873-881

Wearsch PA, Cresswell P (2008) The quality control of MHC class I peptide loading. Curr Opin Cell Biol 20:624-631 
Williams AP, Peh CA, Purcell AW, McCluskey J, Elliott T (2002) Optimization of the MHC class I peptide cargo is dependent on tapasin. Immunity 16:509-520

Wood KJ, Goto R (2012) Mechanisms of rejection: current perspectives. Transplantation 93:1-10. doi:10.1097/T P. 1090b1013e31823cab31844

Wynn KK, Fulton Z, Cooper L, Silins SL, Gras S, Archbold JK, Tynan FE, Miles JJ, McCluskey J, Burrows SR, Rossjohn J, Khanna R (2008) Impact of clonal competition for peptide-MHC complexes on the CD8+ T-cell repertoire selection in a persistent viral infection. Blood 111:4283-4292. doi:10.1182/blood-2007-11-122622
Zarling AL, Luckey CJ, Marto JA, White FM, Brame CJ, Evans AM, Lehner PJ, Cresswell P, Shabanowitz J, Hunt DF, Engelhard VH (2003) Tapasin is a facilitator, not an editor, of class I MHC peptide binding. J Immunol 171:5287-5295. doi:10.4049/jimmunol. 171.10.5287

Zernich D, Purcell AW, Macdonald WA, Kjer-Nielsen L, Ely LK, Laham N, Crockford T, Mifsud NA, Bharadwaj M, Chang L, Tait BD, Holdsworth R, Brooks AG, Bottomley SP, Beddoe T, Peh CA, Rossjohn J, McCluskey J (2004) Natural HLA class I polymorphism controls the pathway of antigen presentation and susceptibility to viral evasion. J Exp Med 200:13-24. doi:10.1084/jem.20031680 